\section{External factors in the development of cataract}

\begin{abstract}
Aims To provide an update on the risk factors for cataract development. Methods Review of the literature. Results Age and heredity are the most important risk factors associated with the different types of cataract. While the hereditary component is self-explanatory, increasing age serves as a surrogate for a number of potential external risk factors, the effect of which is cumulative.

Identification of the risk factors that have a causal effect on cataract development may provide means for cataract prevention. There are only a few risk factors that satisfy the criteria for causal effect: smoking, which results in the increased risk of nuclear cataract, excessive UV-B exposure and diabetes that increase the risk of cortical cataract, and steroidal treatment, diabetes and ionising radiation that lead to the formation of posterior subcapsular opacity. The effect of medications on cataract development requires further study, since the effect of the diseases should be distinguished from that of treatment. 'Stop Smoking' and 'UV-B protection' campaigns are gaining momentum as preventative measures, while the attempts to actively prevent cataract with antioxidants have not been successful. Cataract research has been facilitated lately by improvements of precision and standardisation in measuring lens opacities. However, measurement precision on its own cannot give us a solution to this problem.

Conclusion The major studies repeatedly measure the exposure to the traditional health hazards, while the missing parts in the equation are those risk factors that we do not know about and therefore do not measure. New approaches and new hypotheses are needed.
\end{abstract}

Eye (2005) 19, 1074-1082. doi:10.1038/sj.eye.6701964
L Robman and H Taylor

Keywords: cataract; risk factors; causal associations

Cataract is a major cause of visual disability and blindness, in ageing population presenting enormous financial burdens for both governments and individuals. ${ }^{1}$ Handling a constantly increasing demand for highly successful and cost-effective cataract extraction is a great challenge for the public health system. $^{2}$

Heredity is the major determinant for the development of cataract. ${ }^{3}$ The hereditary component can be responsible for up to $70 \%$ of cataract cases. ${ }^{4}$ The role of genetics has been shown repeatedly through case observations, family studies, and studies on twins. ${ }^{5-8}$ Heritability is clearly not limited to only congenital cataract, but it is also important in the development of age-related nuclear and cortical opacities. ${ }^{5,6,9}$

The term 'external' risk factors for cataract refers to those risk factors that are not hereditary. The origin of nonhereditary agerelated cataracts, is the least understood and the effect of many 'unknown' risk factors is conveniently bundled into 'old age'. For identification of the contributing external risk factors, every hypothesis is important and quantitative analyses of the various possible putative risk factors are needed. However, when cataract is associated with certain diseases such as diabetes, the effects of a genetic predisposition, the disease itself, and its treatment are intertwined, and it can be difficult to determine whether risk is external or internal.

A large number of epidemiological associations were suggested between various health hazards and cataract prevalence. The associated factors can either be merely markers or real causes of the disease. To assess whether the putative risk factors play a causal role, these links should meet several criteria for causal association: temporality, where cause precedes effect; strength, defined as a large relative risk; 
dose-response, showing direct association between larger exposure to cause and higher rates of disease; reversibility, where reduction in exposure is associated with lower rates of disease; consistency in different observations; biological plausibility; and specificity. ${ }^{10}$ Although specificity is not a necessary criterion for risk factors for such a multifactorial disease as is cataract, the putative causes should meet all other listed criteria.

\section{Risk factors for cataract prevalence}

\section{Summary of previous reviews}

Over the last 25 years, there have been a number of epidemiological studies that have examined risk factors for cataract prevalence. The recent reviews with detailed analysis of the findings from these studies ${ }^{11-14}$ showed that only a few risk factors meet the epidemiological criteria for causality. The major causal external risk factors that have been suggested so far are smoking, excessive sunlight exposure and other diseases, or their treatments that change lens metabolism. Others like education, employment, socioeconomic factors, rural residence, or even iris color are most likely markers of pathology and the causes manifested by these markers are yet to be identified.

\section{Smoking}

The results of different studies that examined smoking as a risk factor for nuclear cataract have been reviewed by West and Valmadrid. ${ }^{11}$ This analysis shows a consistency of this association across eight out of 10 studies included in the review. Strength of association, lower cataractogenic effect in past smokers vs current smokers, which addresses the issue of reversibility, and a clear dose-response effect were demonstrated. ${ }^{15-22} \mathrm{~A}$ population-attributable risk of smoking for nuclear cataract can reach $17 \% .{ }^{23}$ Defining smoking as a cause of cataract gave a boost to 'Stop Smoking' campaigns, adding the issue of visual impairment to the issue of mortality from lung cancer, heart disease, and chronic obstructive airways disease.

\section{$U V$-B exposure}

A detailed review by McCarty and Taylor of the epidemiologic evidence from 22 studies on humans ${ }^{14}$ and the review of ecological studies previously conducted by West ${ }^{24}$ showed that lifetime exposure to ultraviolet radiation has a direct association with prevalence of cortical cataract. This was shown in the 15 studies that had different designs, populations, and various levels of exposure to other risk factors. The most convincing data on this association were provided by the studies that quantified individual ocular UV-B exposure and analysed dose response. In the areas with the same level of ambient sunlight, variations in individual behaviour can be a reason for up to a 18-fold difference in UV-B exposure. Sunlight exposure presents an attributable population risk of $10 \%$ for cortical cataract. ${ }^{23} \mathrm{WHO}$ estimates that $20 \%$ of world blindness from cataract may be due to UV radiation exposure. Wearing a brimmed hat and UV-B protecting sunglasses and also avoiding direct sunlight at the peak hours of UV-B radiation have been suggested as a powerful measures of primary prevention for cortical cataract. ${ }^{13,14,23,25,26}$

\section{Diabetes}

'Sugar cataracts' were noticed a long time ago through case observations, before medical treatment became available. Association of these two types of cataract with diabetes mellitus and galactosaemia was proven through biochemical and experimental studies. Higher prevalence and early onset of cortical cataract and posterior subcapsular opacities in diabetic patients was confirmed by clinical studies. ${ }^{11,27}$ It has been suggested that about $4 \%$ of all cataract is attributed to diabetes. ${ }^{28}$ Diabetes as a risk factor for cataract fitted all epidemiological tests for causality except for probably reversibility. An interesting thing to analyse would be whether optimal diabetes control reduces this risk.

\section{Use of steroids}

Reviews by Hodge et $a l^{27}$ and West and Valmadrid ${ }^{11}$ showed that the strength of the association, biologic plausibility, and consistency across studies - all indicate that both systemic and topical steroids are significant risk factors in the formation of posterior subcapsular cataracts. Inhaled steroids have also been shown to increase the risk of cataract. ${ }^{29,30}$ The population attributable risk was estimated by Hodge et $a l^{27}$ as being low since most people are not chronic steroid users. However, the ageing of population together with the advances in surgery, tissue or organ transplantation, treatment of respiratory, rheumatoid, and many other conditions do require steroid use and this escalates the risk.

\section{Alcohol and other factors}

Although alcohol was shown by a number of studies to be a risk factor for different types of cataract, and especially for posterior subcapsular opacities, ${ }^{16,19,31-33}$ the conclusion needs to be drawn carefully, as there is a number of possible biases. The most important concern is that a large number of studies did not report on this association, despite the fact that the information on alcohol intake is routinely collected. Presumably, there was no association. It might be that participants did not 
always provide correct information on this matter, considering it embarrassing. On the other hand, those who participate in health research may be less likely to heavily drink. Also, drinking customs could be traditionally different in different populations. A diverse effect, harmful of heavy drinking and protective of moderate alcohol consumption, was found in the Beaver Dam Eye Study. ${ }^{33}$ No increased risk of alcohol intake on cataract development was found in two Australian population-based studies. ${ }^{34,35}$

A number of other risk factors have been examined, but the results are less consistent across studies. This applies to hypertension, severe dehydration, and malnutrition. A causal role of diseases, where the cataractogenic effect of medications can be difficult to distinguish from the intrinsic effect of the disease needs further investigation.

\section{Recent reports}

Several new reports have been published on the risk factors associated with the prevalence of cataracts since the last major reviews, confirming previously identified associations for smoking, ${ }^{23,34,36,37}$ diabetes, ${ }^{34,38-41}$ and UVB exposure, ${ }^{23,34,36,42-45}$ and indicating new associations that would need further explorations. ${ }^{23,32,34,36,38-40,46}$

Thus, more attention has been paid to systemic diseases and the use of medications. An increased risk of cortical cataract prevalence was associated with the use of amiodarone, ${ }^{46}$ gout duration of greater than 10 years, arthritis and the use of oral beta-blockers, ${ }^{23,34}$ weight change, and use of thyroid hormones. ${ }^{36}$ In contrast to the idea of Vitamin E intake providing protection, an interaction between ocular ultraviolet $\mathrm{B}$ exposure and vitamin $\mathrm{E}^{41}$ was identified as a risk factor for nuclear cataract. Also, an increase of risk for nuclear cataract was associated with the use of phenothiazines ${ }^{46}$ and a decresed risk (protective effect) with the use of nonsteroidal anti-inflammatory drugs. ${ }^{36}$ The risk factors for posterior subcapsular cataract were the use of thiazide diuretics, ${ }^{23}$ antimalarial drug mepacrine, ${ }^{46}$ and, paradoxically, vitamin $\mathrm{E}$ intake $\mathrm{e}^{23}$ and long-term aspirin intake. $^{46}$

An association of high prevalence of cortical cataract with hypertension and abdominal obesity in a black population was reported from the Barbados Eye Study. ${ }^{38}$ In contrast to this, in rural India lean body mass index was found to be harmful, whereas a high waist-to-hip ratio was protective against nuclear and posterior subcapsular cataract. ${ }^{37}$ Regrettably, this study was unable to collect data on nutritional status of the participants.

An association of cataract with use of cheap cooking fuel in India, ${ }^{32}$ will probably need to be further explored.
Since the more factors we choose to analyse, the more likely some statistically significant chance associations could be found, the criterion of consistency across studies becomes increasingly important. Therefore, the aboveindicated associations await confirmation from other studies, conducted on different populations.

Usually, in research on risk factors for cataract prevalence, the data on medical history and personal history of smoking, sunlight exposure, and use of medications are collected in retrospective mode. This approach may show dose-response and can be used to assess the strength of associations. However, prevalence data lack information on the time of onset of the disease and, therefore, cannot fully address the issues of temporality. Identification of the factors associated with the incidence and progression of cataract may shed additional light on the disease process.

\section{Risk factors for cataract incidence and progression}

In the last decade, information on cataract risk factors has emerged from longitudinal studies. Results from the studies investigating risk factors associated with the incidence and progression of different types of agerelated cataract are summarised in chronological order in Table $1 .{ }^{47-53}$

These studies found a significant role of smoking in nuclear cataract progression ${ }^{47,48}$ and confirmed the role of diabetes in the incidence of cortical and PSC cataract. $^{49,50,52}$

Special attention was paid to the medications used by the participants. A 5-year follow-up in the Blue Mountains Eye Study ${ }^{51}$ revealed a three-fold increase of PSC incidence among participants using antihypertensive medications. Although the range of medications could be quite wide, this finding is in agreement with previously reported links between diuretic treatment and changes in lens transparency. It was also found in this study that those with a history of angina were at two-fold risk of having cataract surgery. This finding may need further exploration to determine whether the association was a result of altered metabolism or an effect of treatment for ischaemic heart disease.

The Longitudinal Study of Cataract ${ }^{48}$ found that the medications used for treatment of gout are associated with more than two-fold 4-year risk of nuclear opacification.

In the Barbados Eye Study, ${ }^{50}$ conducted on an Africandescent population, the 4-year incident risk of cortical cataract was five times lower among aspirin users.

The analysis of 678 drugs in relation to 5-year cataract incidence in the Beaver Dam Eye Study ${ }^{52}$ showed a greater than $20 \%$ decreased risk of nuclear cataract 
Table 1 Recent references on risk factors for age-related cataract incidence and progression

\begin{tabular}{lll}
\hline Reference & Details of study, methods of examinations & Results/conclusion \\
\hline West S, 1995. Cigarette smoking and risk for & Cohort study. $N=442$ men & Increase in risk of progression of nuclear opacities to advanced stages among \\
progression of nuclear opacities. Arch & 5 years of follow-up & current smokers compared with that among ex-smokers and nonsmokers. \\
Ophthalmol 113: 1377-1380 & Interviews, lens photo grading & $\begin{array}{l}\text { alcohol use. An 18\% increased risk of progression was significantly associated } \\
\text { aith each pack-year that a subject smoked between 1985 and 1990. }\end{array}$
\end{tabular}

Klein B, 1998. Diabetes, cardiovascular disease, Cohort study N=Aged 43 + Interviews, selected cardiovascular disease risk factors, and the 5-year incidence of age-related cataract and progression of lens opacities: the Beaver Dam Eye Study. American Journal of Ophthalmology 126:782-790

Leske, M., 1998. Risk factors for nuclear opalescence in a longitudinal study. LSC Group. Longitudinal Study of Cataract. Am J Epidemiol 147:36-41

Christen W, 2001. Aspirin use and risk of cataract in posttrial follow-up of Physicians' Health Study. Arch Ophthalmol 119:405-412

Klein, B, 2001. Drug use and five-year incidence of age-related cataracts: The Beaver Dam Eye Study. Ophthalmology 108: 1670-1674

Cohort study, $N=764$

4 years of follow-up

Lens photograding with LOCSIII

Baseline data on possible risk factors

Cohort study. $N=20968$

15 years of follow-up

Post-RCT aspirin use questionnaires, self-

reports on cataract (confirmed by medica

record review) responsible for a reduction

in BCVA to $20 / 30$ or worse and cataract

extraction

Cohort study

Interview, lens photograding

678 drugs (active ingredients) used

Incident cortical and posterior subcapsular cataracts $(P \leq 0.001$ for worse eye for each lesion) and progression of cortical and posterior subcapsular opacities were more common in those with diabetes $(P \leq 0.001$ for either eye for each lesion). Increased glycated haemoglobin level was associated with increased risk of nuclear and cortical cataracts in those with diabetes.

Cardiovascular disease and its risk factors have little effect on the incidence of any age-related cataract.

BMES cohort study, $N=3235$

5 years of follow-up

Risk of nuclear opacification increased in white race $(R R=2.94)$, lower education $(R R=1.50)$, use of gout medications $(R R=2.32)$, current smoking $(R R=1.58)$, family history of cataract $(\mathrm{RR}=1.39)$, and pre-existing posterior subcapsular opacities $(R R=6.67)$. An association with early use of eyeglasses was also suggested $(\mathrm{RR}=1.37)$.

No long-term benefit of 5 years of low-dose aspirin treatment on total cataract or cataract extraction. Post-trial, observational data also indicated no decreased risk of cataract, but a small increased risk in aspirin users: $\mathrm{RR}=1.20$ (95\% CI, 1.031.40). For cataract extraction, the multivariate RR was 1.22 (95\% CI, 0.98-1.51).

Significantly lower incidences of nuclear cataracts 5 years later occurred in those who took thiazide diuretics $(\mathrm{OR}=0.79,95 \% \mathrm{CI} 0.63,1.00)$ and aspirin $(\mathrm{OR}=0.76$, $95 \%$ CI $0.61,0.95)$ at the baseline examination. There were significantly more incident cortical cataracts in those taking oral steroids $(\mathrm{OR}=2.59,95 \%$ CI 1.45 , 4.62), amitriptyline $(\mathrm{OR}=2.03,95 \% \mathrm{CI} 1.09,3.79)$, oral hypoglycaemic agents (OR $2.06,95 \% \mathrm{CI} 1.23,3.44)$, and insulin $(\mathrm{OR}=3.38,95 \% \mathrm{CI} 1.61,7.08)$. There were significantly more incident posterior subcapsular cataracts in those taking potassium-sparing diuretics $(\mathrm{OR}=2.13,95 \% \mathrm{CI} 1.42,3.18)$ and oral hypoglycaemic agents $(\mathrm{OR}=2.89,95 \% \mathrm{CI} 1.57,5.33)$. Hypoglycaemic agents were not associated with any cataract type after stratifying by diabetes status.

Obesity (body mass index $\geq 30 \mathrm{~kg} / \mathrm{m}^{2}$ ) was significantly associated with increased incidence of both cortical $(\mathrm{OR}=1.6,95 \% \mathrm{CI} 1.2-2.2)$ and posterior subcapsular cataract (OR 2.1, CI 1.2-3.7). Hypertensive participants using
Younan C, 2003. Cardiovascular disease, cataract and cataract surgery: the Blue 
among users of thiazide diuretics or aspirin. The risk of incidental cortical cataract was 2.6 times higher among users of oral steroids and two times higher in users of amitriptylin. The risk of posterior subcapsular opacity was two-fold higher in users of potassium-sparing diuretics.

The Physicians' Health Study showed no long-term benefit of 5 years of low-dose aspirin treatment on cataract prevalence or cataract extraction through a randomised control trial. In a post-trial 7-year follow-up study, a small increase of cataract risk was noted among frequent aspirin users, ${ }^{53}$ which is inconsistent with a number of studies, where either a protective effect ${ }^{19,50,52}$ or no association between aspirin use and cataract prevalence was detected. ${ }^{11}$

Such close attention to medications has been justified by the facts that some diseases were associated with higher cataract prevalence, but their causality was hard to prove. Separation of the effect of disease from the effect of medications presents enormous difficulty. Randomised controlled trials are impossible to conduct for this purpose, as it is equally unethical to treat the sick with placebo or to give a potentially harmful active medication to the healthy. However, this separation of effects is a matter of extreme importance, since some drugs may potentially add visual impairment to the suffering of those who are already in pain and poor health.

Thus, longitudinal data tended to confirm the results from the cross-sectional studies on the causal role of smoking and steroidal therapy, showed a strong association with diabetes, and continued controversy in regards to the use of aspirin and diuretics.

Testing of cataract risk factors against the criteria for causality is not always easy or feasible, since the process of the cataract development has a large time span and the causes are most likely concealed in the subject's past.

However, with the development of improved measuring systems for both exposure to risk factors and cataract severity, the epidemiological studies have been successful in the identification of some causes and generated hypotheses for further testing. Probably, the most tempting theory to emerge was that lens opacity results from oxidative damage and that treatment with antioxidants would prevent or slow cataract development. This theory was supported by the assumption that UV-B exposure and smoking, both established risk factors, cause lens damage through oxidation.

This hypothesis was tested in six randomised controlled trials.

\section{Interventional trials}

The cancer prevention trial on 1828 male smokers in Scandinavia found no effect of either vitamin E or 
beta carotene on cataract prevalence after 6.6 years of supplementation. ${ }^{54}$ End-of-trial' eye examinations involved slit and retroillumination photographs.

The other cancer prevention trial studied for 5-6 years a nutritionally deprived population in rural China. The substudies on 2141 subjects in trial 1 and 3249 in trial 2, entitled the Linxian cataract studies, found a beneficial effect of multivitamins and minerals and also of niacin and riboflavin supplementation for nuclear cataract prevention..$^{55}$ End-of-trial examination involved slit and retroillumination photographs.

A randomised trial of 17744 US male physicians noted no effect on cataract incidence or cataract extraction after 13 years of beta carotene use. ${ }^{56}$ Self-reports were the main source of information.

The Age-Related Eye Disease Study (AREDS), a randomised placebo-controlled clinical trial of high-dose supplementation with vitamins $\mathrm{C}, \mathrm{E}$, and beta carotene on 4753 participants, found no effect of this

supplementation on cataract incidence or progression over 7 years of follow-up. ${ }^{57}$ Examination involved slit and retroillumination photographs.

The Vitamin E, Cataract and Age-related macular degeneration Trial (VECAT), conducted on 1193 participants in urban Australia, found no effect of high dose of vitamin $\mathrm{E}$ on either incidence or progression of both cortical and nuclear cataract. ${ }^{58}$ Both subjective clinical cataract grading and computerised, standardised digital Scheimpflug and retroillumination lens imaging produced negative results.

The Roche European-American Anticataract Trial (REACT) on 297 participants, assessing the prevalence and severity of cataract on retroillumination lens images, produced inconclusive results, since no effect on cataract development from the treatment with a combination of antioxidants was noticed in the UK group of participants in contrast to a small protective effect found in the US arm of this study. ${ }^{59}$

Thus, to much disappointment, the results of these interventional trials did not support the very plausible hypothesis of preventing cataracts with antioxidants. However, a potentially protective effect of antioxidant supplements could not be completely ruled out by these trials. Oxidative damage may have an accumulating effect and sufficient damage may occur in younger age. Treatment in the middle age might be too late for antioxidant supplements to repair damage that occurred decades ago. It is possible that lifetime antioxidant supplements might be more protective, although the cost effectiveness of cataract surgery would probably outweigh the benefits of lifelong vitamin supplementation.

\section{Quantification of lens opacity measurements in risk factor assessment}

Improved and more precise assessment of early cataract and its progression is advantageous for lens research and risk factor assessment. Quantification of lens changes has been a major focus for many researchers. As yet there is not a universally accepted system to measure lens changes. Several clinical systems of cataract grading have been suggested..$^{60-70}$ Most of them use a set of standard photos of nuclear opacities and assess the proportion of the pupil occupied by the cortical/PSC opacities.

In the last two decades, different objective measurements of cataract types and disease severity have been developed. Implementing Scheimpflug and retroillumination digital photography with computerised analysis of lens opacities has allowed progression of cataract to be measured with great precision. ${ }^{71-88}$ This method, cost effective for the large epidemiological studies, ${ }^{89}$ is probably the best technique for recording cataract changes.

High-resolution Scheimpflug and retroillumination digital images are repeatable, precise, and highly correlated with clinical cataract grading, although certain artefacts still occur. For example, the images are only black and white; therefore, cases of advanced nuclear brunescence are not adequately assessed. Cortical cataract measurement is difficult to standardise because of variability in pupil dilation that exposes a large or smaller proportion of the lens. Also, irregularities in light reflection from the retina introduce further error in cortical cataract grading. Measurements of posterior subcapsular cataract are less affected by technological artefacts, but a relatively low prevalence of posterior subcapsular cataract means that a very large study size is required to assess the population risks and the effect of risk factors.

Unfortunately, due to low demand, two commercially produced digital lens cameras, the Nidek EAS-1000 and the Oxford CASE 2000, are no longer available.

Although a high level of precision in lens opacity measurements can been reached, most large epidemiological studies have relied on subjective cataract grading, either during slit lamp examination or using photographs taken with a slit lamp.

\section{Discussion}

We tend to accept as inevitable the onset of cataracts that are caused by the use of medications, especially when such treatment is lifesaving. The main purpose of the research into risk factors is to identify modifiable causes of the disease that will provide some basis for cataract prevention strategies. Smoking and sunlight exposure 
are the best examples of causal modifiable external risk factors. 'Stop Smoking' and UV-B protection campaigns have started in some countries and are gaining momentum and impact. However, the burden of cataract surgery does not decrease. One of the possible reasons for this is that improvement in operative technique allows for lifting visual acuity thresholds for cataract surgery. Another reason is that ageing of the population presents an increasing demand for cataract surgery. However, the main reason for this is that the risk factors which have an accumulating effect over years and contributing to the so-called 'age-related' cataract are yet unknown and primary prevention is almost impossible. Preventative measures on smoking and sunlight exposure could result in a relatively small reduction of age-related cataract prevalence, as the populationattributable risks of these factors are lower than $20 \%$. The question arises as to whether the search for risk factors for cataract is far from completion or maybe it is a genetic factor that plays such a major role in this disease, despite the fact that onset of the disease is usually very late.

Our ability to measure both lens opacities and exposure risk factors has significantly improved and this gives us greater precision in assessing the associations. However, despite all the advances in lens research, there has been no major breakthrough in the identification of new risk factors for cataract prevalence, incidence or progression. The need for a large time span for studies, the multitude of confounders, and the fact that epidemiological associations do not necessarily reflect causative links present enormous challenges in ascertaining the true aetiologic factors of age-related cataract. The comparison and integration of the results from different studies is difficult, especially as significant associations tend to be published eagerly and reported widely in the popular press, whereas negative results may not be published at all. Therefore, a few chance findings may outweigh a large body of data showing no associations between a given risk factor and cataract development.

Results from the exhaustive and exhausting randomised controlled trials of antioxidants show that this treatment does not have a significant effect on cataract incidence or progression. 'Stop Smoking' and 'UV-B protection' campaigns are still the only two proven avenues for primary prevention of cataract. Until we know more about cataract risk factors and have greater ability to prevent their onset through primary prevention, the main means to avoid unnecessary low vision and disability from cataract will continue to be secondary prevention through early detection and timely cataract surgery.

\section{References}

1 The World Health Report 1998: Life in the 21st Century: A Vision for All. Geneva: World Health Organization.

2 Rochtchina E, Mukesh BN, Wang JJ, McCarty CA, Taylor HR, Mitchell P. Projected prevalence of age-related cataract and cataract surgery in Australia for the years 2001 and 2021: pooled data from two population-based surveys. Clin Exp Ophthalmol 2003; 31: 233-236.

3 McCarty CA, Taylor HR. The genetics of cataract. Invest Ophthalmol Vis Sci 2001; 42: 1677-1678.

4 Heiba IM, Elston RC, Klein BE, Klein R. Evidence for a major gene for cortical cataract. Invest Ophthalmol Vis Sci 1995; 36(1): 227-235.

5 Hammond CJ, Snieder H, Spector TD, Gilbert CE. Genetic and environmental factors in age-related nuclear cataracts in monozygotic and dizygotic twins. N Engl J Med 2000; 342: 1786-1790.

6 Hammond CJ, Duncan DD, Snieder H, de Lange M, West SK, Spector TD et al. The heritability of age-related cortical cataract: the twin eye study. Invest Ophthalmol Vis Sci 2001; 42: 601-605.

7 Graw J, Loster J. Developmental genetics in ophthalmology. Ophthalmic Genet 2003; 24: 1-33.

8 Francis PJ, Moore AT. Genetics of childhood cataract. Curr Opin Ophthalmol 2004; 15: 10-15.

9 Congdon N, Broman KW, Lai H, Munoz B, Bowie H, Gilber $\mathrm{D}$ et al. Nuclear cataract shows significant familial aggregation in an older population after adjustment for possible shared environmental factors. Invest Ophthalmol Vis Sci 2004; 45(7): 2182-2186.

10 Hill A. The environment and disease. Association and causation. Proc Roy Soc Med 1965; 58: 295-300.

11 West SK, Valmadrid CT. Epidemiology of risk factors for age-related cataract. Surv Ophthalmol 1995; 39: 323-334.

12 Hodge WG, Whitcher JP, Satariano W. Risk factors for agerelated cataracts. Epidemiol Rev 1995; 17: 336-346.

13 Taylor HR. Epidemiology of age-related cataract. Eye 1999; 13: 445-448.

14 McCarty CA, Taylor HR. A review of the epidemiologic evidence linking ultraviolet radiation and cataracts. Dev Ophthalmol 2002; 35: 21-31.

15 Christen WG, Manson JE, Seddon JM, Glynn RJ, Buring JE, Rosner $\mathrm{B}$ et al. A prospective study of cigarette smoking and risk of cataract in men. JAMA 1992; 268: 989-993.

16 Clayton RM, Cuthbert J, Duffy J, Seth J, Phillips CI, Bartholomew RS et al. Some risk factors associated with cataract in S.E. Scotland: a pilot study. Trans Ophthalmol Soc UK 1982; 3: 331-336.

17 Flaye DE, Sullivan KN, Cullinan TR, Silver JH, Whitelocke RA. Cataracts and cigarette smoking. The City Eye Study. Eye 1989; 3: 379-384.

18 Hankinson SE, Willett WC, Colditz GA, Seddon JM, Rosner $\mathrm{B}$, Speizer FE et al. A prospective study of cigarette smoking and risk of cataract surgery in women. JAMA 1992; 268: 994998.

19 Harding JJ, van Heyningen R. Drugs, including alcohol, that act as risk factors for cataract, and possible protection against cataract by aspirin-like analgesics and cyclopenthiazide. Br J Ophthalmol 1988; 72: 809-814.

20 Klein BE, Klein R, Linton KL, Franke T. Cigarette smoking and lens opacities: the Beaver Dam Eye Study. Am J Prev Med 1993; 9: 27-30. 
21 Leske MC, Chylack Jr LT, Wu SY. The lens opacities casecontrol study. Risk factors for cataract. Arch Ophthalmol 1991; 109: 244-251.

22 West S, Munoz B, Emmett EA, Taylor HR. Cigarette smoking and risk of nuclear cataracts. Arch Ophthalmol 1989; 107: 1166-1169.

23 McCarty CA, Nanjan MB, Taylor HR. Attributable risk estimates for cataract to prioritize medical and public health action. Invest Ophthalmol Vis Sci 2000; 41(12): 3720-3725.

24 West S. Ocular ultraviolet B exposure and lens opacities: a review. J Epidemiol 1999; 9: S97-S101.

25 Taylor HR. The biological effects of UV-B on the eye. Photochem Photobiol 1989; 50: 489-492.

26 McCarty CA, Taylor HR. Recent developments in vision research: light damage in cataract. Invest Ophthalmol Vis Sci 1996; 37: 1720-1723.

27 Hodge WG, Whitcher JP, Satariano W. Risk factors for agerelated cataracts. Epidemiol Rev 1995; 17: 336-346.

28 Ederer F, Hiller R, Taylor HR. Senile lens changes and diabetes in two population studies. Am J Ophthalmol 1981; 91: 381-395.

29 Jick SS, Vasilakis-Scaramozza C, Maier WC. The risk of cataract among users of inhaled steroids. Epidemiology 2001; 12: 229-234.

30 Cumming RG, Mitchell P, Leeder SR. Use of inhaled corticosteroids and the risk of cataracts. N Engl J Med 1997; 337: 8-14.

31 Munoz B, Tajchman U, Bochow T, West S. Alcohol use and risk of posterior subcapsular opacities. Arch Ophthalmol 1993; 111: 110-112.

32 Ughade SN, Zodpey SP, Khanolkar VA. Risk factors for cataract: a case control study. Indian J Ophthalmol 1998; 46: 221-227.

33 Ritter LL, Klein BE, Klein R, Mares-Perlman JA. Alcohol use and lens opacities in the Beaver Dam Eye Study. Arch Ophthalmol 1993; 111: 113-117.

34 McCarty CA, Mukesh BN, Fu CL, Taylor HR. The epidemiology of cataract in Australia. Am J Ophthalmol 1999; 128: 446-465.

35 Cumming RG, Mitchell P. Alcohol, smoking, and cataracts: the Blue Mountains Eye Study. Arch Ophthalmol 1997; 115: 1296-1303.

36 Age-Related Eye Disease Study Research Group. Risk factors associated with age-related nuclear and cortical cataract: a case-control study in the Age-Related Eye Disease Study, AREDS Report No. 5. Ophthalmology 2001; 108: 1400-1408.

37 Nirmalan PK, Robin AL, Katz J, Tielsch JM, Thulasiraj RD, Krishnadas $\mathrm{R}$ et al. Risk factors for age-related cataract in a rural population of southern India: the Aravind Comprehensive Eye Study. Br J Ophthalmol 2004; 88: 989-994.

38 Leske MC, Wu SY, Hennis A, Connell AM, Hyman L, Schachat A. Diabetes, hypertension, and central obesity as cataract risk factors in a black population. The Barbados Eye Study. Ophthalmology 1999; 106: 35-41.

39 Delcourt C, Cristol JP, Tessier F, Leger CL, Michel F, Papoz L. Risk factors for cortical, nuclear, and posterior subcapsular cataracts: the POLA study. Pathologies Oculaires Liees a l'Age. Am J Epidemiol 2000; 151: 497-504.

40 Delcourt C, Cristol JP, Leger CL, Descomps B, Papoz L. Associations of antioxidant enzymes with cataract and agerelated macular degeneration. The POLA Study. Pathologies Oculaires Liees a l'Age. Ophthalmology 1999; 106: 215-222.
41 McCarty CA, Nanjan MB, Taylor HR. Attributable risk estimates for cataract to prioritize medical and public health action. Invest Ophthalmol Vis Sci 2000; 41: 3720-3725.

42 Graziosi P, Rosmini F, Bonacini M, Ferrigno L, Sperduto RD, Milton RC et al. Location and severity of cortical opacities in different regions of the lens in age-related cataract. Invest Ophthalmol Vis Sci 1996; 37: 1698-1703.

43 Rochtchina E, Mitchell P, Coroneo M, Wang JJ, Cumming RG. Lower nasal distribution of cortical cataract: the Blue Mountains Eye Study. Clin Exp Ophthalmol 2001; 29(3): 111115.

44 Sasaki H, Kawakami Y, Ono M, Jonasson F, Shui YB, Cheng $\mathrm{HM}$ et al. Localization of cortical cataract in subjects of diverse races and latitude. Invest Ophthalmol Vis Sci 2003; 44: 4210-4214.

45 Neale RE, Purdie JL, Hirst LW, Green AC. Sun exposure as a risk factor for nuclear cataract. Epidemiology 2003; 14(6): 707-712.

46 Cumming RG, Mitchell P. Medications and cataract. The Blue Mountains Eye Study. Ophthalmology 1998; 105: 17511758.

47 West S, Munoz B, Schein OD, Vitale S, Maguire M, Taylor HR et al. Cigarette smoking and risk for progression of nuclear opacities. Arch Ophthalmol 1995; 113: 1377-1380.

48 Leske MC, Chylack Jr LT, He Q, Wu SY, Schoenfeld E, Friend J et al Risk factors for nuclear opalescence in a longitudinal study. LSC Group. Longitudinal Study of Cataract. Am J Epidemiol 1998; 147: 36-41.

49 Klein BE, Klein R, Lee KE. Diabetes, cardiovascular disease, selected cardiovascular disease risk factors, and the 5-year incidence of age-related cataract and progression of lens opacities: the Beaver Dam Eye Study. Am J Ophthalmol 1998; 126: 782-790.

50 Hennis A, Wu SY, Nemesure B, Leske MC, Barbados Eye Studies G. Risk factors for incident cortical and posterior subcapsular lens opacities in the Barbados Eye Studies. Arch Ophthalmol 2004; 122(4): 525-530.

51 Younan C, Mitchell P, Cumming R, Rochtchina E, Panchapakesan J, Tumuluri K. Cardiovascular disease, vascular risk factors and the incidence of cataract and cataract surgery: the Blue Mountains Eye Study. Ophthalmic Epidemiol 2003; 10: 227-240.

52 Klein BE, Klein R, Lee KE, Danforth LG. Drug use and fiveyear incidence of age-related cataracts: The Beaver Dam Eye Study. Ophthalmology 2001; 108: 1670-1674.

53 Christen WG, Ajani UA, Schaumberg DA, Glynn RJ, Manson JE, Hennekens $\mathrm{CH}$. Aspirin use and risk of cataract in posttrial follow-up of Physicians' Health Study I. Arch Ophthalmol 2001; 119: 405-412.

54 Teikari JM, Virtamo J, Rautalahti M, Palmgren J, Liesto K, Heinonen OP. Long-term supplementation with alphatocopherol and beta-carotene and age-related cataract. Acta Ophthalmol Scand 1997; 75: 634-640.

55 Sperduto RD, Hu TS, Milton RC, Zhao JL, Everett DF, Cheng $\mathrm{QF}$ et al. The Linxian cataract studies. Two nutrition intervention trials. Arch Ophthalmol 1993; 111: 1246-1253.

56 Christen WG, Manson JE, Glynn RJ, Gaziano JM, Sperduto $\mathrm{RD}$, Buring JE et al. A randomized trial of beta carotene and age-related cataract in US physicians. Arch Ophthalmol 2003; 121: 372-378.

57 Age-Related Eye Disease Study Research Group. A randomized, placebo-controlled, clinical trial of high-dose supplementation with vitamins $\mathrm{C}$ and $\mathrm{E}$ and beta carotene for age-related cataract and vision loss: AREDS report no. 9. Arch Ophthalmol 2001; 119: 1439-1452. 
58 McNeil JJ, Robman L, Tikellis G, Sinclair MI, McCarty CA, Taylor HR. Vitamin E supplementation and cataract: randomized controlled trial. Ophthalmology 2004; 111: 75-84.

59 Chylack Jr LT, Brown NP, Bron A, Hurst M, Kopcke W, Thien U et al. The Roche European American Cataract Trial (REACT): a randomized clinical trial to investigate the efficacy of an oral antioxidant micronutrient mixture to slow progression of age-related cataract. Ophthalmic Epidemiol 2002; 9: 49-80.

60 Marcantonio JM, Duncan G, Davies PD, Bushell AR. Classification of human senile cataracts by nuclear colour and sodium content. Exp Eye Res 1980; 31: 227-237.

61 Chylack Jr LT. Classification of human cataractous change by the American Cooperative Cataract Research Group method. In: Nugent J, Whelan J (eds). Human Cataract Formation. Bath, Great Britain: Pitman, 1984 pp 3-17.

62 Sparrow JM, Bron AJ, Brown NA, Ayliffe W, Hill AR. The Oxford clinical cataract classification and grading system. Int Ophthalmol 1986; 9: 207-225.

63 Chylack Jr LT, Leske MC, Sperduto R, Khu PM, McCarthy DF. Lens opacity classification system. Arch Ophthalmol 1987; 106: 330-334.

64 Duncan G. On classifying human cataractous lenses. In: Duncan G (ed). Mechanisms of Cataract Formation in the Human Lens. London: Academic Press, 1987.

65 Mehra V, Minassian DC. A rapid method of grading cataract in epidemiological studies and eye surveys. Br J Ophthalmol 1988; 72: 801-803.

66 Taylor HR, West SK. A simple system for the clinical grading of lens opacities. Lens Res 1988; 5: 175-181.

67 Klein BEK, Magli YL, Neider MW, Klein R. Wisconsin system for classification of cataracts from photographs. NTIS Accession No. PB90138306 1989.

68 Sasaki K, Shibata T, Obazawa H, Fujiwara T, Kogure F, Obara Y et al Classification system for cataracts. Application by the Japanese cooperative cataract epidemiology study group. Ophthalmic Res 1990; 22: 46-50.

69 Bailey IL BM, Raasch TW, Taylor HR. Clinical grading and the effects of scaling. Invest Ophthalmol Vis Sci 1991; 32: 422-432.

70 Hockwin O. Cataract classification. Doc Ophthalmol 1994; 88: 263-275.

71 Hockwin O, Dragomirescu V, Laser H. Measurements of lens transparency or its disturbances by densitometric image analysis of Scheimpflug photographs. Graefes Arch Clin Exp Ophthalmol 1982; 219: 255-262.

72 Datiles MB, Edwards PA, Trus BL, Green SB. In vivo studies on cataracts using the Scheimpflug slit lamp camera. Invest Ophthalmol Vis Sci 1987; 28: 1707-1710.

73 Sasaki K, Sakamoto Y, Shibata T, Emori Y. The multipurpose camera: a new anterior eye segment analysis system. Ophthalmic Res 1990; 22: 3-8.
74 Kojima M, Wegener A, Hockwin O. Imaging characteristics of three cameras using the Scheimpflug principle. Ophthalmic Res 1990; 22: 29-35.

75 Sparrow JM, Brown NA, Shun-Shin GA, Bron AJ. The Oxford modular cataract image analysis system. Eye 1990; 4: 638-648.

76 Harris ML, Smith GT, Brown NA. Inter and intra observer reproducibility of the new Oxford ccd Scheimpflug camera. Eye 1991; 5: 487-490.

77 Muller-Breitenkamp U, Hockwin O. Scheimpflug photography in clinical ophthalmology. A review. Ophthalmic Res 1992; 24: 47-54.

78 Wegener A, Hockwin O, Laser H, Strack C. Comparison of the Nidek EAS-1000 system and the Topcon SL-45 in clinical application. Ophthalmic Res 1992; 24: 55-62.

79 Qian W, Soderberg PG, Chen E, Magnius K, Philipson B. A common lens nuclear area in Scheimpflug photographs. Eye 1993; 7: 799-804.

80 Vivino MA, Chintalagiri S, Trus B, Datiles M. Development of a Scheimpflug slit lamp camera system for quantitative densitometric analysis. Eye 1993; 7: 791-798.

81 Magno BV, Freidlin V, Datiles III MB. Reproducibility of the NEI Scheimpflug cataract imaging system. Invest Ophthalmol Vis Sci 1994; 35: 3078-3084

82 Magno BV, Lasa MS, Freidlin V, Datiles MB. Comparison of linear, multilinear and mask microdensitometric analyses of Scheimpflug images of the lens nucleus. Curr Eye Res 1994; 13: 825-831.

83 Datiles III MB, Magno BV, Freidlin V. Study of nuclear cataract progression using the National Eye Institute Scheimpflug system. Br J Ophthalmol 1995; 79: 527-534.

84 Sakamoto Y, Sasaki K. Computed tomographic images and three-dimensional expression of crystalline lens findings from multiple slices of Scheimpflug slit images. Ophthalmic Res 1995; 27: 94-99.

85 Worgul BV, Medvedovsky C, Wu B. Use of non-subjective analysis of lens transparency in experimental radiation cataract research. Ophthalmic Res 1995; 27: 110-115.

86 Foo KP, Maclean H. Measured changes in cataract over six months: sensitivity of the Nidek EAS-1000. Ophthalmic Res 1996; 28: 32-36.

87 Robman LD, McCarty CA, Garrett SK, Stephenson H, Thomas AP, McNeil JJ et al. Comparison of clinical and digital assessment of nuclear optical density. Ophthalmic Res 1999; 31: 119-126.

88 Garrett SK, Robman LD, McCarty CA, Thomas AP, McNeil JJ, Taylor HR et al. Reproducibility of automatic standard digital analysis of lens opacities. ANZJO 1998; 26: S29-S31.

89 Dimock J, Robman LD, McCarty CA, Taylor HR. Digital cataract photography. J Audiovisual Media Med 2000; 23: 7-11. 